\title{
FLIPI-2 Score 1-2, Intermediate Risk
}

National Cancer Institute

\section{Source}

National Cancer Institute. FLIPI-2 Score 1-2, Intermediate Risk. NCI Thesaurus. Code C137660.

A score indicating that a patient has 1-2 risk factors associated with follicular lymphoma and is considered in the intermediate risk group. 